\title{
REFLEXÕES SOBRE A RETÓRICA PEDAGÓGICA: as partes do discurso no ensino da escrita acadêmica
}

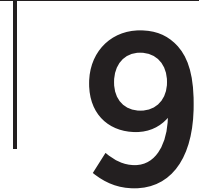

\section{REFLECTIONS ON PEDAGOGICAL \\ RETORIC: the parts of speech applied to academic writing}

FIGUEIREDO, Maria Flávia

Pós-doutora em Língua Portuguesa, pela PUC-SP

Doutora em Linguística e Língua Portuguesa, pela Unesp - Fclar/Araraquara

Docente do Programa de Pós-gradução em Linguística da Universidade de Franca

E-mail: mariaflaviafigueiredo@yahoo.com.br

ORCID: https://orcid.org/0000-0002-7047-4020

\section{SANTOS JÚNIOR, Valmir Ferreira}

Doutorando em Linguística e Língua Portuguesa, pela Universidade de Franca'

E-mail: valmirferreiradossantosjunior@gmail.com

ORCID: https://orcid.org/0000-0003-0431-7542

\section{RESUMO:}

Retórica, disciplina sistematizada na antiguidade clássica, por Aristóteles, tem por fim analisar, por meio do discurso, os meios cabíveis para se chegar à persuasão em cada caso. Tal área, que tem sido matéria de reflexão desde os primórdios da humanidade, possui caráter duplo. Assim, é possível considerar a Retórica como intermediadora de dois campos de atuação: o primeiro, de caráter teórico, voltado para a análise e interpretação de discursos, é empregado na atualidade pelos teóricos e analistas do discurso para ponderar acerca da eficácia, ou não, de determinada estratégia persuasiva componente de um discurso; e o segundo, pertencente à seara prática, voltado para a redação e composição de atos retóricos, é utilizado para guiar retores e oradores em sua prática oratória e persuasiva em âmbito discursivo. O foco deste trabalho repousa sobre a esfera prática, pedagógica, dessa arte. Por meio dos ensinamentos de teóricos e filósofos da antiguidade, o fito da discussão teórica aqui apresentada é auxiliar na atividade de escrita acadêmica, por meio do conceito retórico de partes do discurso, que auxilia na objetividade, clareza e economia de um discurso.

\footnotetext{
1 Bolsista Fapesp de doutorado-direto (processo 2019/01843-8)
} 
Tomaremos, assim, o texto do meio acadêmico como discurso retórico, uma vez que seu intuito é apresentar uma tese a um auditório e fazer com que ela seja aceita. Por fim, este estudo apresentará uma sugestão de composição de um discurso retórico em âmbito científico.

Palavras-chave: Retórica; escrita acadêmica; partes do discurso; Retórica pedagógica.

\section{ABSTRACT:}

Rhetoric, a theoretical subject organized by Aristotle in the Classic era, has the aim to analyze, through discourse, the available means to achieve persuasion in each particular case. This knowledge area has been the matter of discussion and pondering since the genesis of humanity and has a dual face. Therefore, it is possible to understand Rhetoric as both: an analytical tool, employed nowadays by the scholars to interpret the peculiarities of an argumentative/persuasive discourse, when pondered in its success or failure in a discursive way; and as a practical device, capable of guiding those who want to write a rhetorical piece. The main discussion of this study lies on the second face of Rhetoric, the practical, pedagogical, one. Employing knowledge acquired from the classical theorists of this field, the objective of this paper is to aid in academic writing skills, through the rhetorical concept of parts of speech, in the specific skills of objectivity, clarity, and economy. Thus, throughout this discussion, the scientific text will be considered as a rhetorical discourse, once it has the aim to present a particular case to an audience, which, in turn, will decide if it is valid or not. In conclusion, this paper will present a suggestion on academic writing composition in a rhetorical way.

Keywords: Rhetoric; academic writing; parts of speech; Pedagogical Rhetoric.

\section{INTRODUÇÃO}

A interação humana, por meio da linguagem, abarca diversas intencionalidades e funções. Assim, fazemos uso da linguagem, esse mecanismo intercomunicativo, correntemente, nas mais diversas situações. De fato, como seres dotados de racionalidade, é impossível não lançar mão dessa atividade em meio social. Em nossa sociedade integralizada, comunicar é viver. A todo o momento, gerenciamos 
informações: desde as mais banais, como um simples "bom dia", até as mais cruciais, como um pedido de socorro; desde um bilhete despretensioso para alguém da nossa família, até uma carta formal para alguém em um cargo superior ao nosso, na vida profissional. Dessa maneira, todo ato comunicativo possui o intuito de expressar uma mensagem, porém, não é todo e qualquer ato comunicativo que configura o foco deste texto, mas sim aquele que tem por fim a adesão de uma tese, ou seja, sua aceitação por parte daquele(s) que configura $(\mathrm{m})$ o auditório do ato em questão. Dito isso, fica claro que o tipo de ato comunicativo com o qual este texto lidará permeia o campo da Retórica, que pode ser definida brevemente, em sua faceta teórica, como a disciplina que investiga o que é pertinente à persuasão em cada caso e, em seu lado pedagógico, como a matéria que guia na composição de discursos eficazes e bem construídos em termos persuasivos.

De forma elementar, um ato discursivo, ou um ato retórico, comporta três instâncias fundamentais para a sua existência: o orador, o discurso e o auditório. O orador é aquele que redige e profere a mensagem argumentativa, ou seja, é aquele que fala, que emite o discurso. Este, por sua vez, pode ser oral, seja escrito ou composto por qualquer outra linguagem que comporte um sistema argumentativo e significativo capaz de transmitir uma mensagem. Assim, o discurso é a mensagem em si, e, para ser retórico, deve possuir o intuito de convencer e persuadir o auditório a respeito de uma dada questão. Por fim, o auditório é composto por aqueles que recebem, julgam e deliberam sobre o discurso exposto pelo orador. É, no embate com o auditório, que a etapa de enunciação do discurso se concretiza e a etapa de aceitação, ou não, do discurso se inicia. Apresentados os três elementos fundamentais para a existência de um ato retórico, vejamos um breve contexto a respeito da gênese dessa disciplina.

Em meio a essa realidade comunicacional e interacional em que vivemos, a Retórica surge como uma ferramenta crucial em um campo específico da interação humana: o gerenciamento de diferenças a respeito de uma questão polêmica. Como explicita o filósofo belga Meyer (2016), optar pela argumentação é hierarquizá-la em relação ao uso da força, ou seja, a Retórica é uma disciplina em que a lide de questões problemáticas se dá por meio da palavra, da argumentação. Por meio dela, utiliza-se o raciocínio lógico e o apelo emocional em detrimento da força e da violência. 
A Retórica surgiu em meados do século $V$ a.C., na era clássica da Grécia. Os homens livres daquela época, frente a questões que demandavam deliberações, necessitavam de artifícios para persuadir aqueles que julgavam a veracidade de suas afirmações e solicitações e, com isso, surgiram professores que os educavam na arte do bem falar para que seus discursos se tornassem claros, objetivos e, sobretudo, persuasivos.

Apesar da gênese prática, ou pedagógica, da Retórica, a grande vertente dessa disciplina, que perdura até hoje, possui caráter teórico, ou seja, analítico. Isso implica dizer que a Retórica é uma ferramenta de dois vértices, um prático e um teórico. A moeda retórica possui uma face pedagógica, que demonstra aos homens como devem proceder na seara argumentativa, e uma face analítica, que guia aqueles que a usam como lupa para observar a composição persuasiva dos discursos analisados. Uma possível explicação para a valorização atual da face teórica da Retórica seria a importância dos estudos aristotélicos sobre essa temática, que possuíam caráter filosófico, ou seja, reflexivo e analítico.

A obra mais conhecida acerca da arte do bem falar é a Retórica de Aristóteles. Nela, o filósofo de Estagira (antiga cidade da Macedônia, situada hoje na Grécia) organiza os ensinamentos dos professores gregos sobre o tema e sistematiza esse campo do saber. O livro em questão é subdividido em três partes: a primeira lida com a contextualização da temática, apresenta as provas do discurso, os gêneros retóricos e dá atenção especial ao discurso jurídico (de onde surgiu a necessidade de lidar com o discurso persuasivo na antiguidade); a segunda apresenta as provas de caráter psicológico, as paixões, e as provas artísticas, como o entimema e o exemplo; já a terceira parte trata da composição do discurso, perpassando a elocução, o estilo e a ação em um ato retórico. De acordo com o filólogo Gerardo Ramírez Vidal (2019, tradução nossa), o livro III [terceira parte], que trata da atuação, do estilo e da disposição, parece um adendo posterior². Uma vez que é a obra fundamental para qualquer estudioso no assunto, e ela possui caráter analítico e não prático, fica evidente a razão pela qual a face pedagógica da disciplina retórica pode ser considerada subjugada em detrimento de sua irmã analítica.

2 "El libro III, que trata de la actuación, el estilo y la disposición, parece, en efecto, un añadido posterior." 
De fato, os motivos pelos quais a parcela analítica da Retórica detém mais prestígio são irrelevantes para este texto, uma vez que o intuito deste trabalho é evidenciar como tal disciplina pode auxiliar no processo de redação acadêmica. Em geral, espera-se que a Retórica seja uma ferramenta muito valiosa na escrita e na produção de discursos. Sendo assim, este texto se justifica em função da necessidade de se exaltar a Retórica como uma fonte rica na produção discursiva. Apesar de tal riqueza, a disseminação e compartilhamento dos saberes retóricos em sentido pedagógico são pouco discutidos, o que gera a necessidade de demonstrar, de forma clara e didática, como conceitos retóricos milenares podem ser de grande valia para o fazer discursivo na contemporaneidade.

Vejamos como o desenvolvimento deste artigo se dará. Primeiramente partiremos de um breve levantamento bibliográfico, que nos permitirá traçar a diferenciação entre a Retórica analítica, teórica - usada como lupa para observar discursos que tenham por fim a persuasão -, e a Retórica pedagógica - ensinada por mestres gregos e latinos na antiguidade, que tem o intuito de guiar a composição de discursos argumentativos. Em seguida, passaremos à seção "didática" do artigo, em que os conceitos principais serão expostos e descritos. Além disso, nessa seção, o ponto central do trabalho será discutido: como tais conceitos podem ser usados na prática redacional e como eles tornam o texto mais claro, objetivo e, por consequência, persuasivos. Por fim, uma aplicação prática das partes do discurso será apresentada, com o intuito de exemplificar, para o leitor, de que maneira esse conceito retórico pode ser explorado.

\section{LEVANTAMENTO BIBLIOGRÁFICO}

$\mathrm{Na}$ introdução de seu curso "Los argumentos y la argumentación en retórica", Gerardo Ramírez Vidal ${ }^{3}$ assim se pronuncia a respeito da Retórica: "A Retórica é, em grande parte, uma prática e uma teoria sobre a linguagem" (RAMÍREZ VIDAL, 2019, p. 3, grifos e tradução nossos).

Pode-se sintetizar essa citação como o ponto central desta seção. Discutiremos, ao longo desta parte, as duas abordagens retóricas: a

3 Curso de pós-graduação ministrado pelo professor na Universidade de Franca, entre os dias 16 e 19 de setembro de 2019 .

4 "La retórica es, en gran medida, una práctica y una teoría sobre el lenguaje". 
teórica e a pedagógica. De fato, podemos encarar essas duas funções da Retórica como duas faces da mesma moeda, ou seja, na totalidade dessa disciplina, duas funções primordiais guiam aqueles que estudam seus postulados. Antes de definir cada uma delas, vejamos uma breve explanação dessa disciplina, que advém do período clássico da humanidade.

De acordo com o estudioso francês Olivier Reboul,

[...] os gregos inventaram a 'técnica retórica', como ensinamento distinto, independente dos conteúdos, que possibilitava defender qualquer causa e qualquer tese. Depois inventaram a teoria da retórica, não mais ensinada como uma habilidade útil, mas como uma reflexão com vistas à compreensão (REBOUL, 2004, p. XXIII).

É possível ver, então, que os ensinamentos retóricos precederam a teorização desenvolvida por Aristóteles e outros filósofos clássicos. Dessa forma, a gênese retórica se insere, como vimos, no campo pedagógico, prático. Além do universo pragmático em que a Retórica surgiu, é possível depreender em que contexto e meios ela se desenvolveu no ocidente. Vejamos:

A retórica não nasceu em Atenas, mas na Sicília grega por volta de 465, após a expulsão dos tiranos. E sua origem não é literária, mas judiciária. Os cidadãos despojados pelos tiranos reclamaram seus bens, e à guerra civil seguiram-se inúmeros conflitos judiciários. Numa época em que não existiam advogados, era preciso dar aos litigantes um meio de defender sua causa. Certo Córax, discípulo do filósofo Empédocles, e o seu próprio discípulo, Tísias, publicaram então uma 'arte oratória' (tekhné rhetoriké), coletânea de preceitos práticos que continha exemplos para uso das pessoas que recorressem à justiça. Ademais, Córax dá a primeira definição da retórica: ela é 'criadora de persuasão' (REBOUL, 2004, p. 2).

Como visto, a arte do bem falar possui berço jurídico e prático. Era utilizada como ferramenta para estabelecer a justiça e restaurar a ordem. Essa Retórica prática era passada por professores itinerantes que, por intermédio do legado platônico, receberam a denominação de sofistas. As palavras de Reboul ratificam que essa Retórica estava mais voltada para a técnica e era aplicada com o fim de persuadir.

Por outro lado, a Retórica teórica, sistematizada nos escritos aristotélicos, tinha por intuito observar o funcionamento da persuasão dentro de um ato retórico, ou seja, não se configurava como uma 
ferramenta para a prática discursiva, mas principalmente para a análise e observação de discursos.

Dessa forma, é possível observar que as duas vertentes se relacionam diretamente com discursos que possuem intuito persuasivo. Porém, a primeira lida com tais discursos de forma prática, aplicando as ferramentas retóricas e oratórias de forma a redigir e compor um ato retórico efetivo, de acordo com as peculiaridades que o contexto discursivo demanda. Já a segunda, voltada para a reflexão teórica, faz uso das sistematizações em compêndios retóricos de todos os tempos para destrinchar o conteúdo argumentativo e persuasivo dos atos retórico-enunciativos.

Uma vez que a breve distinção entre Retórica pedagógica e Retórica teórica foi feita, é hora de apresentar o conteúdo principal deste artigo, qual seja: a proposição pedagógica, que será pautada no conceito das partes do discurso.

\section{ETAPAS DO PROCESSO RETÓRICO E PARTES DO DISCURSO}

Antes que se trate das partes do discurso, é necessário apresentar de forma breve o percurso pelo qual o bom orador deve passar para redigir seu ato retórico de forma clara, objetiva e persuasiva. Reboul (2004) nos mostra que o processo se decompõe em quatro partes pelas quais um orador passa para a composição de um discurso: invenção (heurésis; inventio); disposição (taxis; dispositio); elocução (lexis; elocutio); e ação (hypókrisis; actio). O autor desconhecido de Retórica a Herenio ${ }^{5}$ discrimina tais partes como "[...] as qualidades que deve possuir o orador" (PSEUDO CÍCERO, 1991, p. 71, tradução nossa).

Em seu artigo intitulado $A$ perspectiva retórica da argumentação: etapas do processo argumentativo e partes do discurso, Figueiredo e Ferreira (2016, p. 58) apresentam um quadro explicativo do caminho que o bom orador deve seguir, ou se acredita que siga, para a composição de um discurso persuasivo eficaz. Vejamos tal quadro para que seja possível realizar uma organização mental dos conceitos que serão discutidos a seguir.

5 A obra, de autor desconhecido, foi atribuída a Cícero por muito tempo. É o tratado de retórica em latim mais antigo que sobreviveu ao tempo, data de aproximadamente 90 a.C. O livro possui esse nome porque foi dedicado a Marcus Herennius, cônsul durante o ano de 93 a.C.

6 "[...] las cualidades que debe tener el orador". 
Figura 1 - Etapas do processo argumentativo e partes do discurso

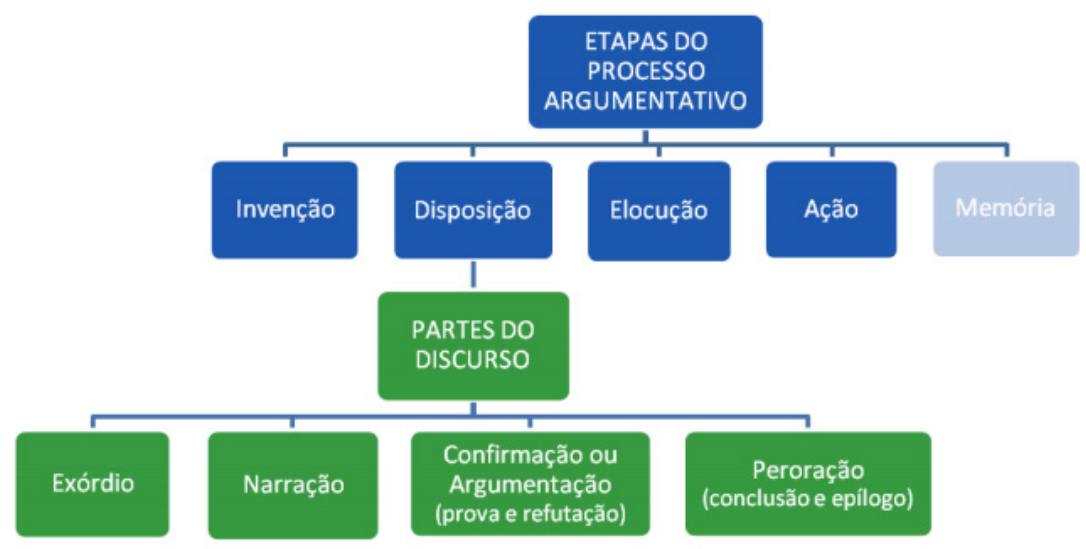

Fonte: Figueiredo e Ferreira, 2016.

De acordo com Figueiredo e Ferreira (2016, p. 46) "a palavra invenção (inventio, em latim, e heurésis, em grego) origina-se do termo latino inventio, que se vincula ao verbo invenire: descobrir, achar, encontrar". De forma elementar, a invenção está relacionada à tarefa de buscar os argumentos que vão compor a defesa da tese apresentada. No momento da invenção, o orador deve lançar mão das provas existentes no mundo que vão ao encontro da posição que defende. Nessa tarefa, ele também deve redigir as provas de cunho psicológico que vão despertar o pathos. Como afirma o autor de Retórica a Herenio, "a invenção é a capacidade de encontrar argumentos verdadeiros ou verossímeis que tornem a causa convincente ${ }^{7 \prime \prime}$ (PSEUDO CÍCERO, 1997, p 71, tradução nossa).

A tarefa da disposição refere-se à forma com que as provas são dispostas, assim, relaciona-se com a ordem em que os argumentos serão ordenados no ato retórico, ou seja, "a disposição ordena e distribui os argumentos e mostra o lugar em que cada um deles deve estar situado8" (PSEUDO CÍCERO, 1997, p. 71, tradução nossa). Nas palavras de Reboul (2004, p. 43), é na disposição que se dá "a ordenação desses argumentos, donde resultará a organização interna do discurso, seu plano". De acordo com os antigos, várias são as ordens

7 "La invención es la capacidad de encontrar argumentos verdaderos o verosímiles que hagan convincente la causa".

8 "La disposición ordena y distribuye los argumentos y muestra el lugar en que debe ser situado cada uno de ellos". 
em que se pode organizar um discurso, mas tal ordem deve deter total atenção do orador, pois ela influenciará diretamente na aceitação, ou não, do discurso. Ainda a respeito das afirmações e proposições dos antigos, para os pensadores gregos, o ponto central de nossa reflexão (as partes do discurso) se insere na etapa da disposição, porém, para alguns filósofos latinos, o ponto central deste texto se encontra na etapa da invenção. Com o intuito de ordenar o raciocínio do leitor, optamos por seguir a ordenação grega e incluir as partes do discurso na dispositio. Voltaremos a essa etapa mais adiante.

A próxima etapa, elocução, lida com a escolha da linguagem por parte do orador para materializar seu ato retórico. Serve para adaptar a seleção dos argumentos advindos da etapa da invenção às palavras adequadas ao contexto retórico específico em que o discurso será proferido. Nessa tarefa, o orador deve se atentar ao contexto em que seu discurso se dará e ao auditório para o qual irá se pronunciar. Vejamos o que Reboul (2004, p. 43) afirma sobre essa etapa: "[...] a elocução (lexis) [...] não diz respeito à palavra oral, mas à redação escrita do discurso, ao estilo. É aí que entram as famosas figuras de estilo, às quais alguns, nos anos 60, reduziam a retórica!". Dessa forma, o discurso deve ser pensado para se adequar à ocasião e ao auditório. A linguagem, o estilo e a densidade do vocabulário devem ser equiparados ao que a situação pede e o auditório demanda.

A última tarefa, a ação, é o momento em que o discurso ganha vida, ou seja, ele passa do processo enunciativo para a enunciação, do abstrato para o material, do plano cognitivo para o plano físico. Essa etapa diz respeito à "[...] capacidade de regular de forma agradável a voz, o rosto e os gestos" ${ }^{\prime \prime}$ (PSEUDO CíCERO, 1997, p. 71, tradução nossa). Na ação, o orador deve se atentar aos seus gestos, movimentação espacial e, logicamente, à sua projeção vocal, prosódica. Vejamos o que o mestre estagirita declara sobre essa etapa:

A pronunciação [ação] assenta na voz, ou seja, na forma como é necessário empregá-la de acordo com cada emoção (por vezes forte, por vezes débil ou média) e como devem ser empregues os tons, ora agudos, ora graves ou médios, e também quais os ritmos de acordo com cada circunstância. São, por conseguinte, três os aspectos a observar: são eles volume, harmonia e ritmo (ARISTÓTELES, 2015, p. 242).

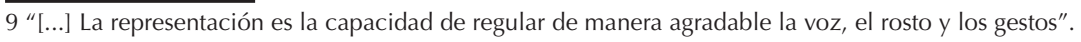


Aristóteles, em sua Retórica, apesar de citar a actio, lida apenas com a inventio, dispositio e elocutio. Em especial, os filósofos latinos Cícero e Quintiliano tratam com mais profundidade da actio e acrescentam outra etapa a esse esquema: a memoria. Tal etapa lida com a memorização de um discurso, de tal forma que ele pareça espontâneo, mas ainda assim garanta ao orador ordenação, fluência e economia em sua exposição.

Resumindo, um orador precisa passar por essas quatro tarefas para compor seu discurso. Quanto mais atenção ele der a cada uma dessas etapas, mais chance de sucesso ele terá. Voltando ao aspecto central de nossa reflexão, vejamos, dentro da disposição, como se alocam as partes do discurso. De acordo com Reboul (2004), as partes do discurso são: exórdio; narração; confirmação; e peroração.

No exórdio temos a contextualização, que pode ser tanto voltada para o auditório, quanto para o orador e, ainda, para o assunto a ser tratado. Quando voltada para o orador, ela deverá angariar a credibilidade do auditório, por meio da projeção de um efeito de autoridade, ou seja, o orador deve se exprimir de tal forma que passe ao seu auditório a ideia de que ele é uma figura qualificada para tratar daquele assunto e, por isso, deve creditar a ele confiança. Quando voltada ao auditório, a função do exórdio é delectare, ou seja, contentar aqueles que testemunham o ato retórico para torná-los dóceis (abertos ao aprendizado) e, assim, obter sua atenção para o tema que será tratado. Por fim, quando lidar com o assunto em questão, o orador deve demonstrar a importância de tratar daquele tema especificamente e frisar a necessidade de abordá-lo, justificando sua escolha. Para angariar a atenção do auditório para o discurso, também é pertinente salientar o quanto o assunto é interessante. O exórdio é também o momento para que o orador forneça ao auditório uma contextualização acerca do tema que será tratado, ou seja, ele pode apresentar, em linhas gerais, a temática a ser abordada no discurso para que todos que tenham contato com seu ato retórico possam compreender seu intuito com aquele discurso. A função primordial do exórdio seria, então, chamar a atenção do auditório, seja para o tema, para o orador ou para o sentimento de deleite a ser suscitado no auditório. Sintetizando nossa proposição a respeito dessa parte do discurso, o autor de Retórica a Herenio assim se pronuncia: "O exórdio [...] serve para conseguir de maneira imediata com que o ouvinte nos 
escute. Seu objetivo é conseguir que os ouvintes se mostrem atentos, interessados e favoráveis ${ }^{10 "}$ (PSEUDO CÍCERO, 1997, p. 75, tradução nossa).

A narração é a segunda parte do discurso e, como o próprio nome expressa, diz respeito à exposição do caso específico do discurso. Nessa parte, o orador ilustra sua causa por meio dos fatos principais. A narração deve ser sintética e clara, ou seja, deve ilustrar apenas os fatos essenciais, ser objetiva e sucinta para que o auditório não se perca em demasiados detalhes e, acima de tudo, deve ser crível. Enquanto, no exórdio, o assunto era a apresentação da temática geral para contextualizar o auditório, na narração, o assunto é a temática específica, que irá introduzir o assunto. Um ótimo meio de ilustrar a narração em um discurso é, justamente, exemplificar ou contar uma história sobre o caso específico. Ao selecionar os fatos que serão apresentados e proceder a essa apresentação de forma ordenada por meio de uma narrativa, o orador pode lograr a atenção de seu auditório de forma muito mais eficaz, uma vez que temos facilidade para visualizar narrativas em nossas mentes. De acordo com o autor de Retórica a Herenio, "uma narração deve possuir três qualidades: brevidade, clareza e verossimilhança ${ }^{11 "}$ (PSEUDO CÍCERO, 1997, p. 82, tradução nossa).

A próxima etapa, a confirmação, é a parte mais densa, mais longa, do discurso. Nela, o orador dispõe todas as provas que sustentam sua tese. Nessa etapa, deve ficar claro o porquê de o auditório aceitar o ponto de vista do orador. É exatamente nessa etapa que o retor inserirá as provas de cunho lógico, exemplos, estatísticas e leis, e psicológico, apelos afetivos, por exemplo. Caso seja pertinente, o orador pode inserir uma refutação nessa parte, demonstrando como uma visão contrária à sua tese não é produtiva para tratar sobre o problema em questão. A confirmação deve ser muito bem redigida, uma vez que é por meio dela que o discurso se sustentará, ou não, conferindo a adesão do auditório, caso afirmativo, ou fracasso do discurso, caso negativo. Por fim, nessa etapa, os argumentos favoráveis e contrários à tese apresentada são ponderados, e essa tarefa deve ser feita de tal forma que a solução apresentada inicialmente se sustente e se apresente

10 "El exordio [...] sirve para lograr de manera inmediata que el oyente nos escuche. Su objetivo es conseguir que los oyentes se muestren atentos, interesados y favorables".

11 "Una narración debe tener tres cualidades: brevedad, claridad y verosimilitud". 
ao auditório como a mais lógica. Em outras palavras, a confirmação deve encaminhar, de forma contundente, o auditório à aceitação da tese do orador. Reboul (2004, p. 57) nos recorda que, após a narração, vem a confirmação, e esta é "[...] nitidamente mais longa", é também "[...] o conjunto de provas, seguido por uma refutação (confutatio), que destrói os argumentos adversários".

Uma vez que estamos adequando tal conceito ao âmbito acadêmico, a parte da refutação, contida na confirmação, pode ser vista como o momento de ruptura com um estudo da mesma seara, por exemplo. Lembrando ainda que nossa proposição possui caráter adaptativo, a refutação pode não ser necessária dependendo das modulações e demandas da escrita em questão.

$\mathrm{Na}$ última parte, a peroração, encontra-se o momento final do discurso. Essa parte pode recapitular toda a argumentação, ampliar o alcance da tese defendida ou ainda apelar às emoções para garantir o processo persuasivo. Como bem menciona Reboul (2004), é nesse momento que o lado lógico se alia ao lado psicológico no discurso. Como podemos ver, essa parte é crucial para o discurso, uma vez que combinará os apelos passionais com as demonstrações lógicas, encaminhando o auditório à persuasão. Nessa parte, então, deve-se apresentar a solução para o problema discutido e concluir o discurso de forma clara.

Como é possível observar, as partes do discurso podem servir como uma ferramenta muito útil para a redação de um discurso persuasivo. Na antiguidade, esse instrumento era utilizado pelos retores para a idealização de seus atos retóricos orais que seriam proferidos diante dos antigos júris e que tinham por fim a obtenção da justiça.

Trazendo esse conhecimento para a contemporaneidade, onde os discursos se tornaram diversos, multifacetados e híbridos, é válido aplicar essa organização a qualquer discurso que tenha por fim a discussão e comprovação de um tema. Dessa maneira, a teoria retórica encontra meios pedagógicos nos dias de hoje por ser aplicável às mais diversas configurações discursivas da atualidade. Essa estratégia retórica pode ser empregada sem grandes problemas, de forma menos rígida (de acordo com o gênero discursivo a que o discurso pertence) aos mais infinitos discursos de nosso tempo, uma vez que o conceito das partes do discurso não serve apenas para elaborar uma ideia, mas também para organizar sua racionalização, para que ela seja acessível 
àqueles que escutam e/ou testemunham o ato da enunciação retórica. Dessa maneira, é possível empregar tal organização em textos dissertativos do meio acadêmico que visam discorrer sobre um assunto e trazer uma conclusão, solução, para uma questão. Ademais, as funções primordiais de cada uma das etapas ainda podem ser aplicadas a qualquer tipo de texto, dentro ou fora do meio acadêmico, compondo, assim, uma ferramenta consiste de escrita.

Para ilustrar as proposições feitas neste artigo, vejamos uma aplicação prática das partes do discurso em um texto do meio acadêmico. $\mathrm{O}$ texto selecionado consiste em um resumo de um projeto de pesquisa. Nele, as partes do discurso foram aplicadas para guiar a linha enunciativa lógica do texto. No item subsequente, o texto será transcrito na íntegra e, em seguida, será dividido para que se observem as características e as devidas partes do discurso discriminadas.

\section{ILUSTRAÇÃO DA PROPOSTA}

\section{Retórica Musical Contemporânea: investigação, delimitação e sistematização}

Desde sua gênese, a música, como uma entidade sociocultural, possui grande importância nos processos e rituais que compreendem a humanidade e, atualmente, tem sido utilizada para inúmeros fins comunicacionais. Tanto na arte, no entretenimento ou em âmbito publicitário, o emprego da música inegavelmente desperta emoções. O estudo desse campo emotivo remonta à Retórica, área do saber que discute as diversas configurações persuasivodiscursivas e que considera, como uma de suas estratégias, o despertar de emoções, paixões. Tudo o que alude às paixões adentra a instância do pathos (um dos três pilares da Retórica), e é na correlação do pathos com a Música que nossa pesquisa se insere. Apesar de óbvios, os efeitos retóricos da música sobre o auditório são pouco explorados em termos científicos, o que resulta em uma lacuna no âmbito acadêmico. Almejando preencher tal lacuna, objetivamos, com este estudo, desvelar esse elo a fim de sistematizar o que defendemos por Retórica Musical Contemporânea como uma área do saber científico. Para tal, desenvolveremos uma pesquisa de cunho explicativoexploratório, em que entrelaçaremos a Retórica e a Música, aplicando-as a um experimento a ser desenvolvido com o auxílio de uma população selecionada. Nessa investigação prática, aplicaremos um protocolo em sujeitos expostos a 
sessões de música. Assim, ao escutar as peças executadas, os sujeitos anotarão, nos protocolos apresentados, suas experiências emotivas e contexto-significativas. Esses protocolos comporão nosso corpus de análise, que será baseada no conceito de Paradigma Indiciário. Esse caminho investigativo nos permitirá rastrear, a partir dos sintomas (emoções despertadas), as causas e explicações do fenômeno em questão, isto é, investigaremos os sinais deixados pela música no campo emotivo de seu auditório. Por meio dessa trajetória, objetivamos compreender, delimitar e lançar as bases para a sistematização da área que denominamos Retórica Musical Contemporânea. (SANTOS JUNIOR, 2019, p. 2).

- Exórdio:

Desde sua gênese, a música, como uma entidade sociocultural, possui grande importância nos processos e rituais que compreendem a humanidade e, atualmente, tem sido utilizada para inúmeros fins comunicacionais. Tanto na arte, no entretenimento ou em âmbito publicitário, o emprego da música inegavelmente desperta emoções.

O excerto do texto, que trata do exórdio, tem a função de fornecer ao auditório a contextualização o assunto, dando um ponto de partida para que seja possível se situar na temática abordada. Nesse caso, o exórdio não está voltado para o orador, muito menos para o auditório, mas sim para o assunto em questão. Dessa forma, o intuito dessa parte é frisar a importância da música para a humanidade de forma geral, uma vez que ela está presente indistintamente nas mais variadas situações de nossas vidas. Assim, o intuito desse exórdio, em específico, é angariar a atenção do auditório para a temática tratada.

- Narração:

Tanto na arte, no entretenimento ou em âmbito publicitário, o emprego da música inegavelmente desperta emoções. O estudo desse campo emotivo remonta à Retórica, área do saber que discute as diversas configurações persuasivo-discursivas e que considera, como uma de suas estratégias, o despertar de emoções, paixões. Tudo o que alude às paixões adentra a instância do pathos (um dos três pilares da Retórica), e é na correlação do pathos com a Música que nossa pesquisa se insere. Apesar de óbvios, os efeitos retóricos da música sobre o auditório são pouco explorados em termos científicos, o que 
resulta em uma lacuna no âmbito acadêmico. Almejando preencher tal lacuna, objetivamos, com este estudo, desvelar esse elo a fim de sistematizar o que defendemos por Retórica Musical Contemporânea como uma área do saber científico.

Aqui, a narração possui a finalidade de "contar" o caso específico, a relação da música com a Retórica que culmina na área citada no texto como "Retórica musical contemporânea". De forma geral, o texto se torna mais específico, não tratando mais da música na vida humana, mas da música que tem por fim um objetivo persuasivo. A demonstração do caso específico é feita por meio da apresentação dos aspectos necessários para caracterizar o ponto central do texto, a nova ramificação da Retórica.

- Confirmação:

Para tal, desenvolveremos uma pesquisa de cunho explicativoexploratório, em que entrelaçaremos a Retórica e a Música, aplicandoas a um experimento a ser desenvolvido com o auxílio de uma população selecionada. Nessa investigação prática, aplicaremos um protocolo em sujeitos expostos a sessões de música. Assim, ao escutar as peças executadas, os sujeitos anotarão, nos protocolos apresentados, suas experiências emotivas e contexto-significativas. Esses protocolos comporão nosso corpus de análise, que será baseada no conceito de Paradigma Indiciário. Esse caminho investigativo nos permitirá rastrear, a partir dos sintomas (emoções despertadas), as causas e explicações do fenômeno em questão, isto é, investigaremos os sinais deixados pela música no campo emotivo de seu auditório.

O parágrafo acima apresenta a forma com que o estudo será desenvolvido, ou seja, por quais meios os pesquisadores envolvidos chegarão a concretizar a sistematização dessa nova seara retórica. Pode-se analisar essa parte como a redação de uma prova que tem por intuito comprovar que o caminho estabelecido é profícuo para alcançar o objetivo sinalizado. Assim, a confirmação pode ser detectada nessa parte uma vez que lida com a demonstração de um argumento que viabiliza a aceitação da tese apresentada.

- Peroração:

Por meio dessa trajetória, objetivamos compreender, delimitar e lançar as bases para a sistematização da área que denominamos 
Retórica Musical Contemporânea.

Como se trata de um texto acadêmico, não há necessidade de se apelar ao lado passional do auditório, uma vez que as construções particulares desse âmbito discursivo se pautam muito mais nas projeções do logos do que nas do pathos. Dessa forma, fica claro o motivo de o texto não aliar a emoção ao racionamento lógico. Porém, a função da peroração que se pode exaltar nesse trecho é a recapitulação. Nele, é possível identificar a restauração do objetivo central do estudo, com vistas a deixar claro para o auditório o ponto principal do texto.

Por meio do texto aqui seccionado, buscamos demonstrar que as partes do discurso podem funcionar como estratégia para o desenvolvimento de um texto com progressão, em que se tenha em mente o ponto de partida (uma questão abrangente que lide com a temática trazida pelo texto, por meio do exórdio), se desenvolva na questão específica (cerceando a questão abrangente até alcançar o ponto a ser tratado de forma aprofundada, por meio da narração e da confirmação) e que se conclua salientando a contribuição ou ponto essencial do discurso (trazendo apelo às emoções ou, no caso do texto científico, conclamando à razão por meio de estratégias como a recapitulação, na peroração).

\section{CONSIDERAÇÕES FINAIS}

Como discutido desde a introdução deste artigo, a Retórica é uma disciplina dotada de dois vértices, um que se debruça sobre os discursos para compreendê-los em suas composições persuasivas e outro que é utilizado para guiar aqueles que possuem o intuito de redigir enunciados claros, objetivos e que angariem a aceitação daqueles que se apresentam como auditório.

Tais vértices compõem essa arte milenar, que, apesar de tão antiga, detém conceitos extremamente necessários para qualquer ser humano, em qualquer área de atividade contemporânea, visto que seu cerne é a comunicação. Assim, a Retórica se apresenta como um dispositivo altamente profícuo na composição, organização e exposição dos mais variados tipos de discursos, permeando as mais diversas áreas comunicacionais.

Enquanto a vertente teórica da Retórica guia os analistas e acadêmicos no trabalho interpretativo com os textos, apontando as 
construções e organizações das configurações discursivas, o lado prático serve para qualquer pessoa que se interesse em tornar suas composições discursivas mais efetivas.

Neste texto, almejamos demonstrar como um dos conceitos basilares da Retórica, as partes do discurso, pode ser utilizado para guiar a redação textual, em específico, a redação acadêmica.

Visto que um texto de cunho científico pode ser enquadrado em uma esfera discursiva que possui o intuito de comunicar uma ideia e, fundamentalmente, fazer com que os leitores aceitem as proposições e teses defendidas por seu redator, podemos considerá-lo essencialmente retórico. Por sua vez, por deter as características de um texto de caráter retórico, os gêneros acadêmicos têm a se beneficiar do arcabouço da arte do bem falar, quando redigidos de acordo com os preceitos e as orientações dos mestres e pensadores dessa arte milenar.

Em síntese, o presente artigo constituiu uma tentativa de demonstrar o quanto é possível se beneficiar da instância pedagógica da Retórica em âmbito acadêmico. As partes do discurso não estão restritas apenas ao discurso oral, muito menos presas aos moldes clássicos dos atos retóricos do passado. O que se espera com este texto é exaltar a profundidade e riqueza da Retórica em esferas discursivas contemporâneas, demonstrando sua aplicabilidade em contextos atuais e de corrente circulação nas mais diversas situações comunicacionais.

Concluímos que o conceito de partes do discurso guiou não apenas a redação do resumo selecionado como matéria de estudo e exercício, mas também toda a elaboração deste texto, o que pode demonstrar sua aplicabilidade também em diversas outras estruturas redacionais, exaltando assim a Retórica, área do saber que abarca conhecimentos que extrapolam a seara analítica e que podem auxiliar na vida prática de todos aqueles que desejam aprimorar suas habilidades discursivo-interacionais.

\section{REFERÊNCIAS}

ARISTÓTELES. Retórica. Tradução do grego por Manuel Alexandre Júnior, Paulo Farmhouse e Abel do Nascimento Pena. São Paulo: Folha de S. Paulo, 2015. (Coleção Folha. Grandes nomes do pensamento; v. 1).

FIGUEIREDO, M. F.; FERREIRA, L. A. A perspectiva retórica da argumentação: etapas do processo argumentativo e partes do discurso. ReVel. Edição especial, v. 14, n. 12, 2016, p. 44-59. 
MEYER, M. Questões de retórica: linguagem, razão e sedução. Tradução de António Hall. Lisboa: Edições 70, 2016.

PSEUDO CÍCERO. Retórica a Herenio. Introdução, tradução e notas por Salvador Núñes. Madrid: Gredos. 1997.

RAMÍREZ VIDAL, G. Los argumentos y la argumentación en retórica. 16-19 de set. de 2019. 51 p. Notas de Aula.

REBOUL, O. Introdução à retórica. Tradução de Ivone Castilho Benedetti. 2. ed. São Paulo: Martins Fontes, 2004.

SANTOS JUNIOR, V. F. dos. Retórica musical contemporânea: investigação, delimitação e sistematização. 20p. Projeto de pesquisa (Doutorado em Linguística) - Programa de Pós-Graduação em Linguística, Universidade de Franca, Franca / FAPESP - Fundação de Amparo à Pesquisa do Estado de São Paulo.

Enviado em: $\quad$ 09/12/2019

Aceite em: $\quad$ 18/12/2019 